\title{
Avaliação de fontes e doses de fósforo no crescimento inicial do milho
}

\section{Evaluation of sources and rates of $P$ fertilizers on the initial growth of corn}

\author{
Nelson Harger'; Osmar R. Brito ${ }^{2 *}$; Ricardo Ralisch; \\ Fábio Rogério Ortiz ${ }^{3}$; Toshio Sérgio Watanabe ${ }^{4}$
}

\begin{abstract}
Resumo
O fósforo é componente vital para todos os seres vivos e é essencial para a produção agrícola. No Brasil, a maior parte dos solos agricultáveis tem baixos teores de fósforo disponível. Para atender as exigências das plantas e suprimento adequado de fósforo há a necessidade da aplicação de adubos fosfatados. Dentre as opções de fontes no mercado, os fosfatos totalmente acidulados são os usualmente comercializados. Com o aumento do uso dos fosfatos naturais reativos, a avaliação da efíciência da aplicação do fertilizante é importante no manejo da adubação fosfatada. O experimento foi realizado em casa de vegetação, utilizando um Nitossolo. $\mathrm{O}$ delineamento experimental empregado foi o inteiramente casualizado com os tratamentos arranjados em um fatorial 4 x 2 com quatro repetições. O objetivo do trabalho foi avaliar os efeitos de fontes e doses de fósforo no crescimento inicial do milho. A produção de matéria seca e os teores de $\mathrm{P}$ da parte aérea das plantas de milho aumentaram com o incremento das doses de fósforo, independentemente da fonte de $\mathrm{P}$ considerada. Contudo, o Superfosfato Triplo foi mais eficiente que o fosfato de Arad, garantindo melhor nutrição e crescimento inicial das plantas de milho.
\end{abstract}

Palavras-chave: Zea mays, adubação fosfatada, fosfatos acidulados, fosfatos naturais reativos

\begin{abstract}
Phosphorus is an essential element for all living organisms and important also for agricultural production. The content of P in most agricultural soils in Brazil is low. In order to supply the plant needs and the soil fixation, application of $\mathrm{P}$ fertilizer is required. Among the various options of $\mathrm{P}$ fertilizers in the market, the totally acidified phosphates are usually commercialized. The evaluation of the efficiency of the reactive natural phosphates as $\mathrm{P}$ fertilizers is important due to the increase of the utilization of cheaper sources of natural P. The experiment was carried out in green house, using a Nitossolo. The experimental design used was complete randomized design, with the treatments in a $4 \times 2$ factorial arrangement, and four replications. The objective of the experiment was to evaluate the effects of sources and rates of $\mathrm{P}$ on the growth of corn. The production of dry matter and the content of $\mathrm{P}$ on the corn leave and stalks (above ground corn parts) increased as rates of $\mathrm{P}$ increased, regardless the $\mathrm{P}$ sources tested. However, the Triple Super Phosphate was more efficient compared with Arad phosphate, providing better nutrition and initial growth of corn plants.
\end{abstract}

Key words: Zea mays, phosphate fertilization, acidified phosphates, natural reactive phosphates

1 Doutorando do Programa de Pós-Graduação em Agronomia - UEL. Eng. Agrônomo, M Sc. Implementador Regional da Emater Pr. E-mail: nelsonharger@emater.pr.gov.br.

2 Professores do Dep. de Agronomia, UEL.

3 M Sc., Assistente de Pesquisa, Embrapa Soja.

${ }^{4}$ Eng. Agrônomo, M Sc. Coordenador técnico do GDT de Mauá da Serra - Pr

* Autor para correspondência: UEL, CP 6001, CEP. 86.051-990. Londrina. 


\section{Introdução}

O milho tem sido cultivado no Brasil nas mais variadas condições de clima e solo. A produtividade da cultura depende, dentre outros fatores, do adequado suprimento de nutrientes, sendo o fornecimento de $\mathrm{P}$ via adubação uma prática essencial nos solos brasileiros. Nas plantas, o fósforo é necessário para fotossíntese, respiração, transferência de genes e em processos que envolvem transferência de energia (STAUFFER; SULEWSKI, 2003). É parte integrante de diversas moléculas químicas, como açúcares fosfatados, nucleotídios, coenzimas, fosfolipídios, ácido fítico, além de ser parte estrutural do difosfato de adenosina (ADP) e do trifosfato de adenosina (ATP). Está relacionado com o crescimento das raízes, maturação de frutos, formação de grãos, frutos e fibras e com o vigor das plantas. (VITTI; WIT; FERNANDES, 2004).

Nas adubações, o fósforo é geralmente fornecido às plantas na forma de fertilizantes fosfatados solúveis por ocasião do plantio. Devido à alta capacidade de adsorção de fósforo nos solos argilosos, altas doses são necessárias para obter produções comerciais. Para contornar o problema dos custos dos fosfatos solúveis obtidos pelos processos convencionais de solubilização, vem sendo proposto o uso de fontes alternativas de fósforo.

Dentre as opções de fontes de fósforo no mercado, os fosfatos totalmente acidulados são os usualmente comercializados, entre eles os grupos dos superfosfatos simples e triplos, e dos fosfatos monoamônicos e diamônicos. Como exemplos de uso de fontes alternativas estão os fosfatos naturais reativos na forma farelada (PROCHNOW; ALCARDE; CHIEN, 2004), com aumento da sua utilização nos últimos anos pelo menor custo e facilidade de distribuição nas adubações. Isso ocorreu porque até 1992 a legislação estabelecia a comercialização dos fosfatos de origem sedimentar na forma moída (no mínimo $85 \%$ das partículas menores do que $0,074 \mathrm{~mm}$ ) com dificuldades na aplicação. A partir de 2003, nova legislação definiu sua utilização na forma farelada ( $100 \%$ das partículas menores do que $4 \mathrm{~mm}$ e no mínimo $80 \%$ delas menores do que $2,8 \mathrm{~mm}$ ), classificados como fosfatos reativos (HOROWITZ; MEURER, 2004).

Os resultados de pesquisas e as indicações técnicas para o uso dos fosfatos naturais reativos substituindo as fontes solúveis, ainda suscitam dúvidas quanto ao melhor manejo das fontes dos adubos fosfatados. Fertilizantes de menor reatividade ao disponibilizarem mais lentamente o $\mathrm{P}$, poderiam favorecer maior eficiência de utilização do nutriente pelas culturas (NOVAIS; SMITH, 1999; LOPEZ, 1999).

A eficiência da aplicação do fertilizante fosfatado ao solo e as necessidades nutricionais das plantas, influenciam na seleção de técnicas de manejo da adubação fosfatada. Assim, os métodos de avaliação são baseados em possíveis aumentos da quantidade de matéria seca proporcionado pela adubação, fósforo acumulado ou produtividade, proporcionados pela aplicação de fósforo em relação a uma fonte padrão de fósforo. (KORNDORFER; CABEZAS; HOROWITZ, 1997). O presente trabalho teve por objetivo avaliar o efeito de fontes e doses de fósforo sobre o crescimento inicial do milho.

\section{Material e Métodos}

O experimento foi realizado em casa de vegetação, pertencente ao departamento de Agronomia da Universidade Estadual de Londrina, utilizando amostras de Nitossolo, coletado na camada de 0-20 cm em área de pastagem na comunidade de Bom Jesus, em Cambira, Pr. Em seguida, após seco ao ar e passado em peneira de $2 \mathrm{~mm}$ (T.F.S.A.), cerca de $200 \mathrm{~g}$ de solo destinaram-se para as análises químicas (PAVAN et al., 1992) (Tabela 1). 
Tabela 1. Características químicas do Nitossolo utilizado no experimento.

\begin{tabular}{|c|c|c|c|c|c|c|c|c|}
\hline $\begin{array}{c}\mathrm{pH} \\
\mathrm{CaCl}_{2} \\
0,01 \mathrm{M}\end{array}$ & $\mathrm{Ca}^{++}$ & $\mathrm{Mg}^{++}$ & $\mathrm{K}^{+}$ & $\mathrm{Al}^{+++}$ & $\mathrm{H}+\mathrm{Al}$ & CTC & $\begin{array}{c}\mathrm{P} \\
\mathrm{mgdm}^{-3}\end{array}$ & $\begin{array}{c}\mathrm{MO} \\
\mathrm{g} \mathrm{kg}^{-1}\end{array}$ \\
\hline 4,9 & 5,60 & 1,80 & 0,15 & 0,0 & 6,21 & 13,76 & 1,03 & 31,14 \\
\hline
\end{tabular}

$\mathrm{MO}=$ Matéria orgânica $\mathrm{CTC}=$ capacidade de troca catiônica, $\mathrm{pH} 7,0$.

Utilizou-se no experimento vasos com capacidade para $2,5 \mathrm{~kg}$ de solo. Antes da semeadura foi feita a adubação em dose única, a $5 \mathrm{~cm}$ de profundidade, equivalente a $40 \mathrm{~kg} \mathrm{ha}^{-1}$ de nitrogênio (uréia) e $30 \mathrm{~kg}$ $\mathrm{ha}^{-1}$ de $\mathrm{K}_{2} \mathrm{O}$ (cloreto de potássio). A semeadura foi feita com três sementes da cultivar OC 705, deixando uma planta de milho por vaso após o desbaste. Durante o período experimental a umidade do solo foi mantida em 70\% da capacidade máxima de retenção de água do solo, com reposição da água evapotranspirada mediante a diferença da pesagem diária dos vasos.

Aos 26 dias após a emergência foram avaliadas as produções de matéria seca das plantas de milho e os teores de fósforo no limbo foliar e parte aérea do milho. Estes foram encaminhados ao laboratório, lavados conforme metodologia descrita em Malavolta, Vitti e Oliveira (1997) e colocados em estufa com circulação forçada de ar, mantida à temperatura constante de $65^{\circ} \mathrm{C}$. Para avaliação específica dos teores foliares de fósforo, foram utilizados o terço médio das folhas de cada planta, eliminando-se a nervura principal. Os extratos de leitura para fósforo foram obtidos por digestão nitroperclórica das amostras de material seco. Para leitura do fósforo de cada extrato, utilizou-se a metodologia do azul de molibdênio (MALAVOLTA; VITTI; OLIVEIRA, 1997). O delineamento experimental empregado foi o inteiramente casualizado com os tratamentos arranjados em um fatorial 4 x 2 com quatro repetições em que os fatores foram quatro doses de fósforo $(0,60,120$ e $180 \mathrm{~kg}$ ha $^{-1}$ de $\mathrm{P}_{2} \mathrm{O}_{5}$ ), e duas fontes de fósforo (superfosfato triplo e fosfato natural reativo de Arad), aplicados por ocasião da semeadura. Os dados foram submetidos à análises de variância, ajustados a equações polinomiais de regressão e submetidos ao teste de Tukey a 5\% de significância.

\section{Resultados e Discussão}

Para os teores de P no limbo foliar e parte aérea do milho a partir da fonte superfosfato triplo e teores de fósforo no limbo foliar a partir da fonte Arad, todas as doses diferiram estatisticamente da testemunha. Já para teores de P na parte aérea na fonte Arad, não houve diferença estatística para as doses testadas. Ainda, os teores de P no limbo foliar e parte aérea das plantas de milho sempre foram maiores quando se utilizou o superfosfato triplo, indicando a melhor nutrição da planta (Tabela 2 e Figura 1). Este efeito está diretamente associado à maior velocidade de liberação do nutriente pelo fosfato solúvel, minimizando o efeito da competição solo/planta, pois segundo Novais e Smyth (1999), a fixação do fósforo pelos colóides do solo se dá de forma preferencial. Utilizando a equação de ajuste, foi possível estimar que os valores máximos para os teores de $\mathrm{P}$ para o limbo foliar de nas plantas de milho, foram obtidos com a aplicação de 129 e $197 \mathrm{~kg}$ de $\mathrm{P}_{2} \mathrm{O}_{5}$ ha $^{-1}$ para o superfosfato triplo e fosfato de Arad, respectivamente. 
Tabela 2. Teores de fósforo nas folhas e parte aérea de milho aos 26 dias após emergência.

\begin{tabular}{cccc}
\hline Fonte & Doses & P foliar & P parte aérea \\
\hline & ${\mathrm{kg} \mathrm{de} \mathrm{P}_{2} \mathrm{O}_{5} \mathrm{ha}^{-1}}^{*}$ & $\mathrm{~g} \mathrm{~kg}^{-1} \mathrm{MS}$ \\
Superfosfato triplo & 0 & $0,99 \mathrm{Ac}^{*}$ & $1,83 \mathrm{Ab}$ \\
& 60 & $3,80 \mathrm{Ab}$ & $3,67 \mathrm{Aa}$ \\
& 120 & $4,48 \mathrm{Aa}$ & $3,81 \mathrm{Aa}$ \\
& 180 & $4,75 \mathrm{Aa}$ & $4,83 \mathrm{Aa}$ \\
\hline \multirow{2}{*}{ Fosfato de Arad } & 0 & $0,99 \mathrm{Ab}$ & $1,83 \mathrm{Aa}$ \\
& 60 & $2,97 \mathrm{Ba}$ & $2,24 \mathrm{Ba}$ \\
& 120 & $3,38 \mathrm{Ba}$ & $2,85 \mathrm{Aa}$ \\
& 180 & $4,16 \mathrm{Ba}$ & $3,97 \mathrm{Aa}$
\end{tabular}

*Médias seguidas de letras iguais, maiúsculas entre fontes dentro de cada dose e minúsculas entre doses dentro de cada fonte não diferem entre si pelo teste Tukey a 5\% de significância.

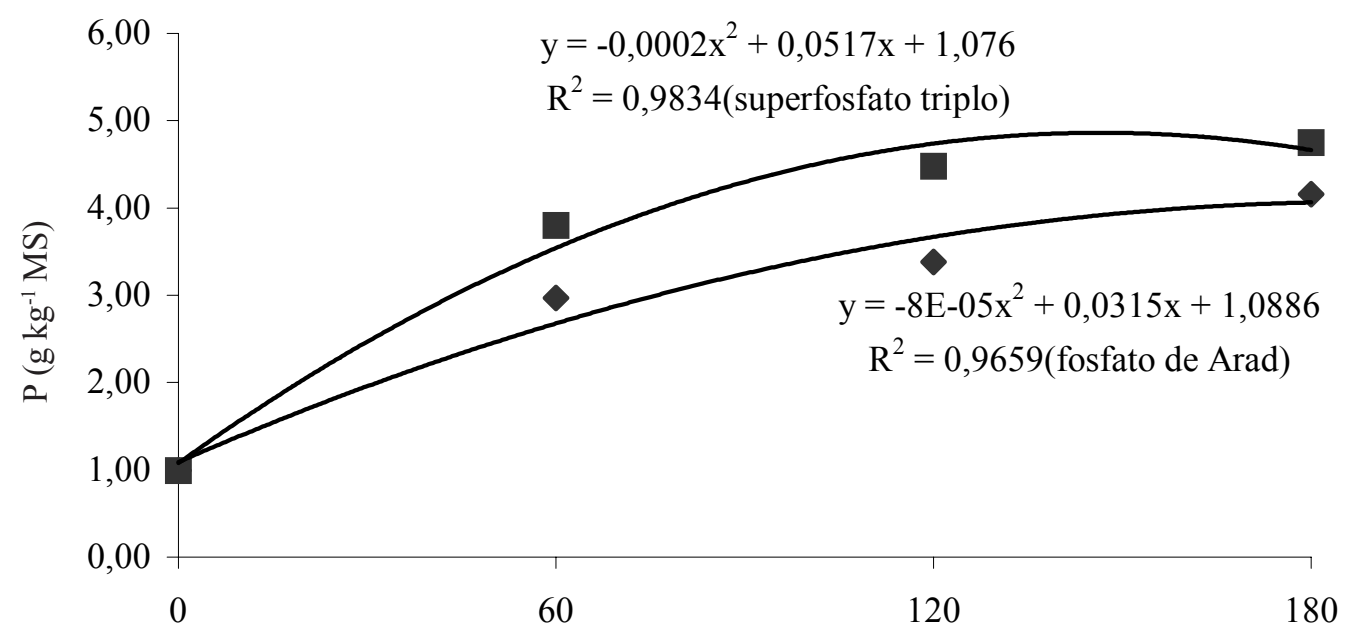

$\mathrm{kg} \mathrm{P}_{2} \mathrm{O}_{5} \mathrm{ha}^{-1}$

Figura 1. Teores de fósforo nas folhas de milho em função de doses e fontes de fósforo.

Para a produção de matéria seca da parte aérea a partir da fonte superfosfato triplo, todas as doses diferiram estatisticamente da testemunha, e os dados obtidos se ajustaram a uma função quadrática. Neste caso a produção máxima foi obtida com as dose de $131,06 \mathrm{~kg}$ de $\mathrm{P}_{2} \mathrm{O}_{5}$ ha $^{-1}$. Para o fosfato natural de Arad, todas as doses com exceção de $60 \mathrm{~kg}$ de $\mathrm{P}_{2} \mathrm{O}_{5}$ $\mathrm{ha}^{-1}$ diferiram estatisticamente da testemunha. Os dados obtidos ajustaram-se linearmente indicando que as doses testadas não foram suficientes para atender a demanda das plantas.

Quando comparados os resultados das duas fontes dentro de cada dose para os teores de P no limbo foliar, parte aérea e a produção de matéria seca do milho; houve diferença estatística significativa para as fontes testadas, caracterizado pela maior eficiência da fonte superfosfato triplo, garantindo melhor nutrição e crescimento inicial das plantas de milho. 
Tabela 3. Produção de matéria seca (MS) da parte aérea de plantas de milho em função de doses e fontes de fósforo.

\begin{tabular}{|c|c|c|}
\hline Fonte & Doses & MS parte aérea \\
\hline \multirow{5}{*}{ Superfosfato triplo } & $\mathrm{kg}$ de $\mathrm{P}_{2} \mathrm{O}_{5} \mathrm{ha}^{-1}$ & g planta $^{-1}$ \\
\hline & 0 & $0,77 \mathrm{Ab}^{*}$ \\
\hline & 60 & $13,39 \mathrm{Aa}$ \\
\hline & 120 & $12,60 \mathrm{Aa}$ \\
\hline & 180 & $13,38 \mathrm{Aa}$ \\
\hline \multirow{4}{*}{ Fosfato de Arad } & 0 & $0,78 \mathrm{Ab}$ \\
\hline & 60 & 3,09 Bab \\
\hline & 120 & $3,81 \mathrm{Ba}$ \\
\hline & 180 & $4,50 \mathrm{Ba}$ \\
\hline
\end{tabular}

*Médias seguidas de letras iguais, maiúsculas entre fontes dentro de cada dose e minúsculas entre doses dentro de cada fonte não diferem entre si pelo teste Tukey a 5\% de significância.

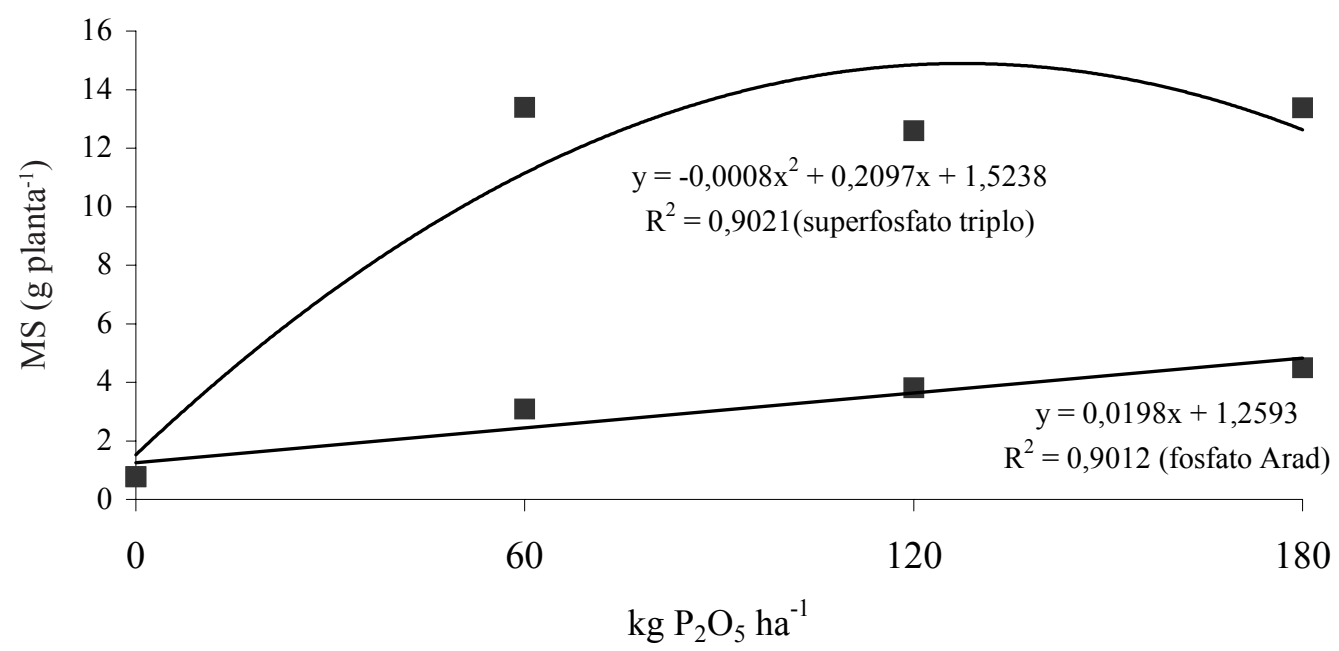

Figura 2. Produção de matéria seca (MS) da parte aérea de plantas de milho em função de doses e fontes de fósforo.

Na possibilidade de obter o mesmo incremento de produção máxima de matéria seca obtida com a superfosfato triplo (15,26 g por vaso), seria necessário aplicar a dose equivalente a 707,106 $\mathrm{kg}$ de $\mathrm{P}_{2} \mathrm{O}_{5}$ ha $^{-1}$ utilizando o fosfato de Arad. Estes resultados estão de acordo com aqueles obtidos por Silva et al. (1999), que verificaram a menor eficiência dos fosfatos naturais quando comparadas com fontes solúveis.

\section{Conclusões}

A produção de matéria seca da parte aérea das plantas de milho aumentou com o incremento das doses de fósforo, independentemente da fonte de $\mathrm{P}$ considerada.

$\mathrm{O}$ aumento das doses de $\mathrm{P}$ propiciou aumentos nos teores foliares de $\mathrm{P}$ nas plantas de milho, para as duas fontes estudadas. 
O superfosfato triplo foi a fonte de fósforo de maior eficiência, garantindo melhor nutrição e crescimento inicial das plantas de milho.

\section{Referências bibliográficas}

HOROWITZ, N.; MEUER, E. J. Eficiência agronômica dos fosfatos naturais. In: YAMADA, T.; ADDALLA, S. R. S. In: SIMPÓSIO SOBRE FÓSFORO NA AGRICULTURA BRASILEIRA. 1., 2004, Piracicaba. Anais... Piracicaba: POTAFOS, 2004. p.666-667.

KORNDORFER, G. H.; CABEZAS, W. A. L.; HOROWITZ, N. Eficiência agronômica de fosfatos naturais na cultura da milho. In: CONGRESSO BRASILEIRO DE CIÊNCIA DO SOLO, 26., Rio de Janeiro. Resumos... Campinas.: SBCS, 1997.p. 145

LOPEZ, A. S. Fosfatos naturais. In: RIBEIRO, A. C.; GUIMARÃES, P. T. G.; ALVAREZ, V. H., Recomendações para o uso de corretivos e fertilizantes em Minas Gerais. Viçosa: Comissão de fertilidade do solo do Estado de Minas Gerais, 1999. p.65-66.

MALAVOLTA, E.; VITTI, G. C.; OLIVEIRA, S. A. Avaliação do estado nutricional das plantas: princípios e aplicações. Piracicaba: POTAFOS, 1997.
NOVAIS, R. F.; SMITH, T. J. Fósforo em solo e planta em condições tropicais. Viçosa: UFV-DPS, 1999. p.62-64.

PAVAN, M. A.; BLOCH, M. D. M.; ZEMPULSK, H. C.; MIYAZAWA, M.; ZOCOLER, D. C. Manual de análises clínicas e controle de qualidade. Londrina: IAPAR, 1992. (IAPAR, Circular 76).

PROCHNOW, L. I.; ALCARDE J. C.; CHIEN, S. H. Eficiência agronômica dos fosfatos totalmente acidulados. In: SIMPÓSIO SOBRE FÓSFORO NA AGRICULTURA BRASILEIRA. 1., 2004, Piracicaba. Anais... Piracicaba: POTAFOS, 2004. p.606-609.

SILVA, D. J. ; ALVARENGA, R. C. ; ALVAREZ, V. H. ; SOARES, P. C. Localização de fósforo e de cálcio no solo e seus efeitos sobre o desenvolvimento inicial do milho. Revista Brasileira de Ciência do Solo, Campinas, v.17, p.203-209, 1999.

STAUFFER, M. D.; SULEWSKI, G. Fósforo: nutriente essencial para a vida. Informações Agronômicas, Piracicaba, n.102, p.1-2, 2003.

VITTI, G. C.; WIT, A.; FERNANDES, B. E. P. Eficiência agronômica dos termofosfatos e fosfatos reativos naturais. In: SIMPÓSIO SOBRE FÓSFORO NA AGRICULTURA BRASILEIRA. 1., 2004, Piracicaba. Anais... Piracicaba: POTAFOS, 2004. p.690-694. 